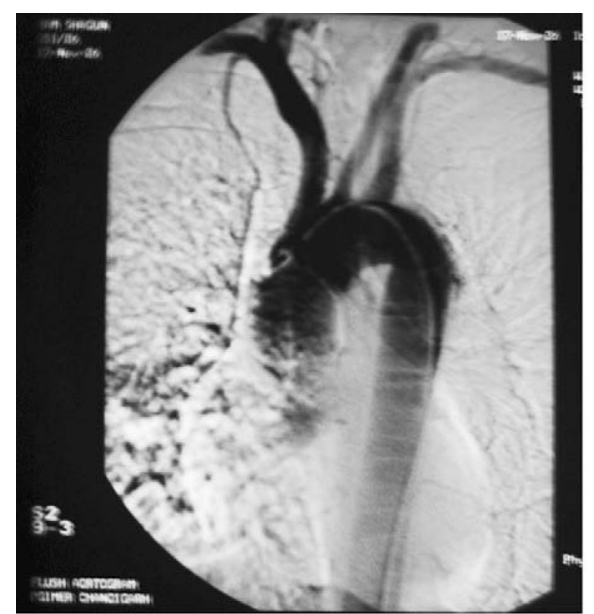

A

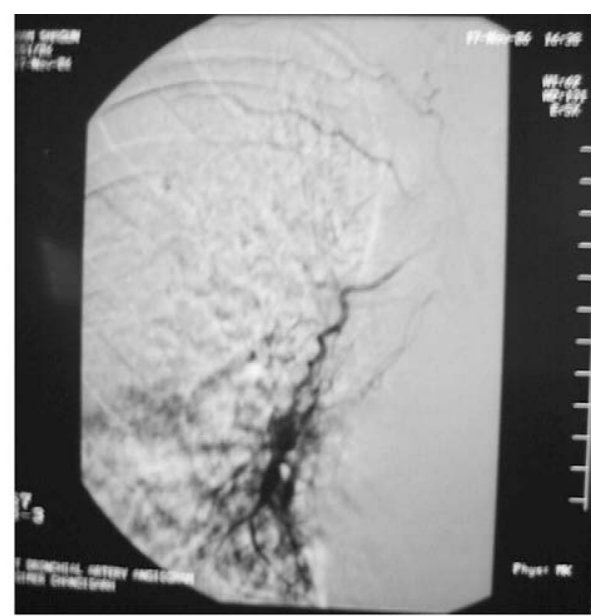

B

FIGURE 1. Digital subtraction angiogram showing filling of a branch of the right bronchial artery from the thoracic aorta (A) and filling of the hemangiomatous portion through the right bronchial artery (B).

\section{References}

1. Brundage BH, Gomez AC, Cheitlin MD, Gmelich JT. Systemic artery to pulmonary vessel fistulas-report of two cases and a review of the literature. Chest. 1972;62:19-23.
2. Riehl G, Chaffanjon P, Frey G, Sessa C, Brichon PY. Postoperative systemic artery to pulmonary vessel fistula: analysis of three cases. Ann Thorac Surg. 2003;76:1873-7.

\title{
Early calcification of a stentless pericardial bioprosthesis in the elderly
}

\author{
Maria Grazia Croccia, MD, ${ }^{\mathrm{a}}$ Stefano Pratali, MD,${ }^{\mathrm{a}}$ Cristina Basso, MD, PhD, ${ }^{\mathrm{b}}$ Giovanni Scioti, MD,${ }^{\mathrm{a}}$ Mila Della Barbera, BSc, PhD, ${ }^{\mathrm{b}}$ \\ Gaetano Thiene, MD, ${ }^{\mathrm{b}}$ and Uberto Bortolotti, MD, ${ }^{\mathrm{a}}$ Pisa and Padova, Italy
}

The Sorin Freedom pericardial valve (SFP, Sorin BiomedicaCardio, Saluggia, Italy), a stentless bioprosthesis made of glutaraldehyde-tanned bovine pericardium, was introduced clinically in $1991 .{ }^{1}$ In 2000 , detoxification treatment with homocysteic acid was added to eliminate glutaraldehyde toxicity and mitigate tissue calcification. The SFP has shown excellent overall results at medium term with no cases of structural failure. ${ }^{2}$ We report the first case of early SFP calcification in an elderly recipient.

\footnotetext{
From the Section of Cardiac Surgery, University of Pisa Medical School, ${ }^{a}$ Pisa, Italy, and Cardiovascular Pathology, University of Padova Medical School, ${ }^{\mathrm{b}}$ Padova, Italy.

Received for publication Feb 28, 2008; accepted for publication March 8, 2008.

Address for reprints: Uberto Bortolotti, MD, Sezione Autonoma di Cardiochirurgia

Universitaria, Dipartimento Cardiotoracico e Vascolare, Via Paradisa 2, 56124

Pisa, Italy (E-mail: u.bortolotti@cardchir.med.unipi.it).

J Thorac Cardiovasc Surg 2009;137:1273-5

$0022-5223 / \$ 36.00$

Copyright (c) 2009 by The American Association for Thoracic Surgery

doi:10.1016/j.jtcvs.2008.03.042
}

\section{CLINICAL SUMMARY}

An 84-year-old woman underwent aortic valve replacement in 2000 with a 25 -mm SFP, implanted with 3 continuous sutures of 4-0 polypropylene to secure the inflow and outflow rims; intraoperative echocardiography showed a competent valve. Approximately 6 years later she was hospitalized for acute pulmonary edema. A harsh precordial systolic murmur was audible, and electrocardiography showed sinus rhythm and left ventricular hypertrophy. Echocardiography revealed calcified valve cusps with a peak transvalvular gradient of $100 \mathrm{~mm} \mathrm{Hg}$ and a valve area of $0.8 \mathrm{~cm}^{2}$. No evident risk factors for bioprosthetic calcification were detected; renal function was normal (serum creatinine $0.78 \mathrm{mg} / \mathrm{dL}$ ) with no hyperlipidemia, and hyperparathyroidism was excluded by normal calcium and phosphate values. At reoperation, the prosthesis appeared incorporated into the aortic wall; all cusps were calcified (Figure 1), and calcification extended to the outflow of the prosthesis preventing its complete removal. The 3 cusps were separately excised leaving a rigid diminutive aortic 

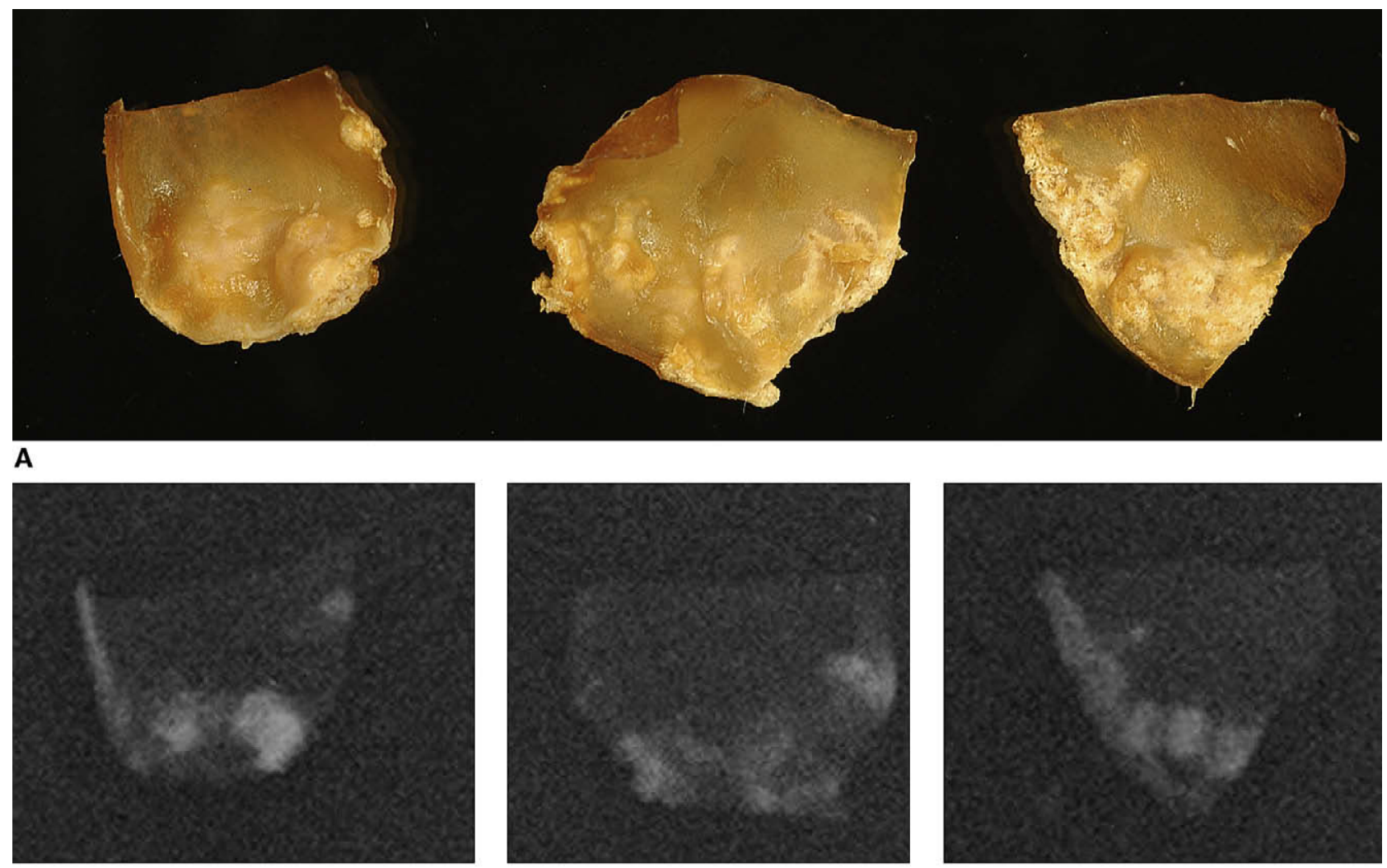

B
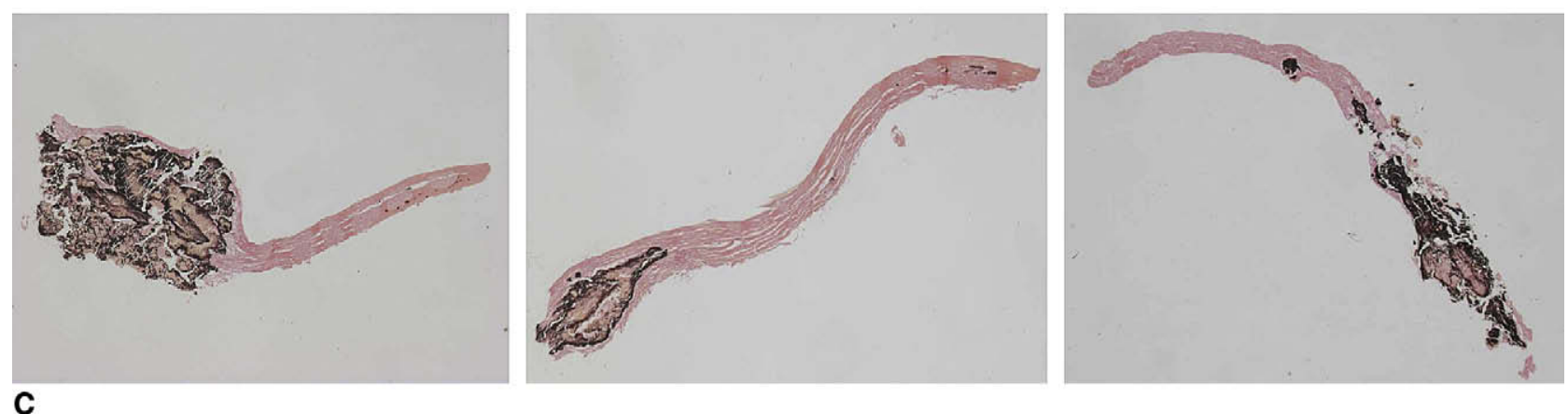

FIGURE 1. Gross (A), x-ray (B), and histologic (C) views of the explanted cusps with massive calcification (von Kossa stain, magnification $\times 6$ ).

annulus; this was enlarged with a patch of bovine pericardium allowing the insertion of a 21-mm Perimount Magna pericardial bioprosthesis (Edwards Lifesciences, Irvine, Calif). The patient recovered uneventfully.

\section{DISCUSSION}

Intrinsic calcification is the leading cause of bioprosthetic failure and reoperation. In the elderly, mineralization of bioprostheses occurs slowly, thus justifying their extended use in this patient subset because the prosthesis will most likely outlive the recipient. ${ }^{3}$ Stentless bioprostheses have been reported to be hemodynamically superior to stented bioprostheses and with potentially longer durability, thus gaining popularity in recent years as a valve substitute in the elderly. ${ }^{4}$
The SPF is a stentless bioprosthesis made entirely of bovine pericardium with excellent hemodynamic performance and durability at medium term, with no reports of valve mineralization. The present case shows 2 interesting features. First, it describes early bioprosthetic calcification in an elderly patient without evident risk factors after aortic valve replacement with a first-generation $\mathrm{SPF}$, a prosthesis without any antimineralization treatment. Bioprosthetic calcification in the elderly is considered exceptional. ${ }^{5}$ Because such a complication has not been reported even in large series of patients receiving an $\mathrm{SPF},{ }^{2,4}$ our case may be an occasional finding. Second, it underlines the potential complexity of replacing a stentless valve, which might require a more technically demanding procedure. In our case, the 
presence of a small, rigid aortic annulus mandated an annular enlargement procedure to insert a prosthesis of adequate size, and calcification of the prosthesis outflow discouraged the use of a second stentless valve.

\section{References}

1. Stacchino C, Bona G, Rinaldi S, Vallana F. Design and performance characteristics of the Pericarbon stentless valve. J Heart Valve Dis. 1995;4(Suppl I): S102-5
2. D'Onofrio A, Auriemma S, Magagna P, Favaro A, Cannarella A, Piccin C, et al Aortic valve replacement with the Sorin Pericarbon Freedom stentless prosthesis: 7 years' experience in 130 patients. J Thorac Cardiovasc Surg. 2007;134:491-5.

3. Bortolotti U, Scioti G, Milano A, De Carlo M, Codecasa R, Nardi C, et al. Performance of 21-mm size Perimount aortic bioprosthesis in the elderly. Ann Thorac Surg. 2000;69:47-50.

4. Nyawo B, Graham R, Hunter S. Aortic valve replacement with the Sorin Pericarbon Freedom stentless valve: five-year follow-up. J Heart Valve Dis. 2007;16:42-8.

5. Polo ML, Legarra JJ, Vilar M, Cabrera A, Duran D, Pradas G. Early calcification of a Carpentier- Edwards Perimount mitral valve in an elderly woman. J Thorac Cardiovasc Surg. 2002;124:1043-4.

\title{
Acute rupture of both papillary muscles after aortic valve replacement for infective endocarditis
}

\author{
Rony Atoui, MD, MSc, ${ }^{\mathrm{a}}$ Tarek Hijal, MD, ${ }^{\mathrm{a}}$ Richard Fraser, MD, ${ }^{\mathrm{b}}$ and Dominique Shum-Tim, MD, MSc, ${ }^{\mathrm{a}}$ Montreal, Quebec, Canada
}

Surgical treatment of active infective valvular endocarditis is associated with substantial morbidity and mortality, particularly when the infection spreads below the primary infected valve. We report the case of a patient in whom acute mitral regurgitation (MR) developed secondary to the rupture of both papillary muscles (PMs) after aortic valve replacement (AVR) for infective endocarditis.

\section{CLINICAL SUMMARY}

A previously healthy 23-year-old morbidly obese man was transferred to our hospital with a 5-day history of left-sided chest pain, dyspnea, cough, and fever. On arrival, his blood pressure was $120 / 48 \mathrm{~mm} \mathrm{Hg}$, with a regular pulse rate of 148 beats/min, a temperature of $38.6^{\circ} \mathrm{C}$, a respiratory rate of 26 breaths/min, and an oxygen saturation of $86 \%$ on room air. The only remarkable physical findings were a grade III/ VI long, diastolic, blowing murmur at the right second interspace and a progressively decreasing level of consciousness, with no focal neurologic signs. After intubation, a transesophageal echocardiogram revealed the presence of a $1 \times 3-\mathrm{cm}$ vegetation involving the right and left aortic leaflets and associated with severe aortic insufficiency with an ejection fraction of $30 \%$. There was no evidence of abscess, and the anterior mitral leaflet was intact with minimal MR.

\footnotetext{
From the Division of Cardiac Surgery ${ }^{\mathrm{a}}$ and Department of Pathology, ${ }^{\mathrm{b}}$ McGill University Health Center, Montreal, Quebec, Canada.

No financial associations or conflicts of interest to disclose.

Received for publication March 12, 2008; revisions received March 12, 2008; accepted for publication March 21, 2008.

Address for reprints: Dominique Shum-Tim, MD, MSc, Division of Cardiothoracic Surgery, McGill University Health Center, 1650 Cedar Avenue, Montreal, Quebec, H3G 1A4, Canada (E-mail: dshumtim@yahoo.ca).

J Thorac Cardiovasc Surg 2009;137:1275-6

$0022-5223 / \$ 36.00$

Copyright (c) 2009 by The American Association for Thoracic Surgery

doi:10.1016/j.jtcvs.2008.03.043
}

The patient was taken to the operating room for an emergency AVR. Under cardiopulmonary bypass, an aortotomy was performed and the aortic valve (AV) was excised. A 2$\mathrm{cm}$ aortic abscess involving the ventricular septum was identified. After thorough debridement of all the infected tissue, reconstruction of the aortic annulus was achieved using bovine pericardium followed by insertion of a number $21 \mathrm{St}$ Jude mechanical valve (St Jude Medical Inc, St Paul, Minn).

Postoperatively, the patient's condition gradually improved. However, on postoperative day 4, the patient's fever spiked to, his white count increased to 37.5 , his systolic pressure decreased to $70 \mathrm{~mm} \mathrm{Hg}$, and his wedge pressure increased to $28 \mathrm{~mm} \mathrm{Hg}$. Shortly thereafter, cardiac arrest occurred and the patient died after attempted resuscitation for more than 30 minutes.

Examination of the heart at autopsy revealed a competent $\mathrm{AV}$ with no vegetation or thrombus. However, both the anterior and posterior PMs were ruptured and the posteroseptal myocardium contained a $2.5 \times 1.5-\mathrm{cm}$ abscess (Figure 1). Histologic examination showed myocardial necrosis and marked acute inflammation of both papillary heads, consistent with septic embolization of the small coronary branches supplying these muscles. Gram-positive cocci, consistent with Group B streptococcus found in blood cultures, were identified in the necrotic tissue. Additional foci of septic embolization were seen in the kidneys and spleen.

\section{DISCUSSION}

Aortic root infection occurs in one third of all patients with native valve endocarditis and is associated with substantial morbidity and mortality. ${ }^{1}$ The major determinants for the successful surgical management of these cases are the complete exclusion and thorough debridement of the infected cavities. ${ }^{2} \mathrm{MR}$ in the setting of $\mathrm{AV}$ endocarditis is 